\title{
Experiments in optics for younger students by and for older students
}

\section{James Masi}

James V. Masi, "Experiments in optics for younger students by and for older students," Proc. SPIE 2525, 1995 International Conference on Education in Optics, (13 October 1995); doi: 10.1117/12.224018

SPIE Event: SPIE's 1995 International Symposium on Optical Science, Engineering, and Instrumentation, 1995, San Diego, CA, United States 
Experiments in optics for younger students

by and for older students

James V. Masi

Western New England College, Department of Electrical Engineering

Springfield, MA 01119

\begin{abstract}
Under the auspices of a joint NSF/DOE grant for science and mathematics, the Electrical Engineering Department of the Engineering School at Western New England College developed a program of instruction in optics and optical applications for local Junior High School students. College level juniors and professors in the electrical engineering department, after the juniors had taken a one semester introductory course in optics and electro-optics, served as instructors in teaching and laboratory instruction in such diverse areas as solar cells/light detection, light sources, simple optics, optical fibers, liquid crystals, and lasers. Concepts such as seismic monitoring, Fourier transforms, power generation, information transfer, and many other applications were explained at level by the college students to the junior high school students with great effectiveness. Students at the lower level caught the enthusiasm of those at the upper level and learned with retention. Seven years into the program, the pros and cons are presented, the now-college bound students and their observations are detailed, and the learning experience for all is assessed, with scenarios for alternate programs suggested.
\end{abstract}

Keywords: optics, experiments, education, pre-college, college.

\title{
1. INTRODUCTION
}

In an attempt to interest students in optics while they are still in pre-college grades, a program was undertaken in 1987 by the Electrical Engineering Department of Western New England College under the auspices of the National Science Foundation and the Department of Energy joint grant for science and mathematics. Students in their junior year of college, who had taken an introductory course in optics and electro-optics, joined with professors from the electrical engineering department to instruct junior high school level students in a variety of subject matter associated with optics and electro-optics by means of a hands-on, mini-lecture and experimental experience. The younger students in this program had been exposed to basic algebra, angle measurement and trigonometric functions, basic materials science, and electrical measurements and concepts through previous modules given in the program. In addition to the professors and college students who taught on a regular basis, there were guest lecturers from industry, industrial site visits (eg. Galileo Electro-Optics, Coherent, Spectran, United Technologies, etc.), and video demonstrations.

The students were responsible for keeping their own written logbook and writing a laboratory report for each experiment. A research shadow experience was given to sets of four students paired with a graduate student or a professor. A report on this research experience was delivered by each student group to the assembled class during the last class of the module. Parents were invited to this last class of the module which was held on a Saturday. The classes in these modules were given over the summer break, with extension classes given one day per week (in the afternoon following their regular day's classes at the junior high schools) during the regular school year. During the summer classes, recreation (pool, tennis, basketball, etc.) was the final activity of the day and food was supplied to all participants during the day.

\section{THE COLLEGE STUDENT'S PREPARATION}

The third year college students took a course called "Introduction to Electro-Optics", which was a one semester course taught in the spring semester just preceding the summer NSF/DOE program. The topical matter included the following subjects: Light, Geometrical Optics, Wave Phenomena, Elements of Solid State Physics, Modulation of Light, Display Devices ( Luminescence, photo- and electro-, Plasma, Liquid Crystal Devices, etc.), Lasers, Photodetectors, Fiber-Optic Waveguides, and Optical Communication Systems (Free-space, fiber optic, system design, and integrated optics), and 
Holography. This course may be taught from any suitable book which covers a sufficiently wide topical range. ${ }^{1}$ The course included four, self-directed laboratories coordinated with the subject matter. These experiments were: Simple Lenses, Mirrors, and Diffraction; Data Transmission and Transducers Using Fiber Optics; Lasers and Holography; and Liquid Crystal Displays. The college students for the NSF/DOE program were chosen, by the professor of record, from the students who had taken this course. The students received pay for the summer program and were expected to continue into the following fall and spring semesters of the school year with the after-school program as well. A training period of two weeks preceded the summer program. In this training period, the college students were expected to perform the junior high school experiments with the professor, prepare and set up laboratories, and coordinate all activities with the professor in charge.

\section{THE JUNIOR HIGH SCHOOL EXPERIMENTS}

The seven experiments chosen for the junior high school experiments were: Lenses; Luminescence; Fiber Optics; Solar Cells/Detectors; Liquid Crystal Displays; Lasers; and Holograms. A typical group working on a laboratory is shown in Figure 1. Each week of the module, two of the experiments were performed, with alternation between two groups of students on successive weeks. The students were responsible for keeping their own written logbook and writing, in the classroom in rough draft, a laboratory report for each experiment. During the last weeks of the summer program, a research shadow experience was given to sets of four students paired with a graduate student and/or a professor. This experience involved such areas as: Image Deblurring; Fiber Optic Chemical Sensors; Making a plastic laser; Laser Vibration Analysis of Tools; Fabrication and Test of a Novel LCD Device; and Holograms for Non-Destructive Test. A typical experience with a Laser tensile test vibration monitor is shown in Figure 2. A report on this research experience was delivered by each student group to the assembled class during the last class of the module. Parents were invited to this last class of the module which was held on a Saturday. The outline of the program delivered to the junior high school students is given in Table 1.

I. Lenses

a. Equations for thin lenses

b. Equations for thick lenses

c. Computer program (RAYTRACE) ${ }^{2}$

d. Magnifiers, microscopes, telescopes, gradient index, diffractive optics

e. Verification on optical bench

II. Luminescence

a. Basics of energetics: excitation and emission

b. Fluorescence, examples/observations

c. Phosphorescence, examples/observations

d. Cathodoluminescence, examples/observations

e. Chemiluminescence, examples/observations

f. Gaseous luminescence, examples/observations

III. Fiber Optics

a. Basics of light trapping/total internal reflection

b. Power budgets ${ }^{3}$

c. Light sources and sensors

d. Slab visualization of light trapping and measurements

e. Illuminators/light conduits

f. Image reformers

g. Data/voice transmission

h. Attenuation/vibration measurements
Table 1

EXPERIMENTS/SUBTOPICS

IV. Solar Cells

a. Solar Energy

b. Basics of photovoltaics

c. Current -voltage characteristics

d. Current/voltage vs area/light intensity

e. Running a motor

f. Calculating maximum power

V. Liquid Crystal Displays

a. Basic principles

b. Different types (dynamic scattering, twisted nematic, cholesteric)

c. Voltage vs transmission

d. Speed of response

e. Devices made from L.C. materials

VI. Lasers

a. Basics of spontaneous vs stimulated emission, modulation, laser light show

b. Gas, solid state, injection, dye

c. Communications over free space with gas and injection lasers

d. Diffraction and Fourier transforms (CD's, Ronchi rulings, and Bragg deflectors)

VII. Holography

a. Basics of holography/sand mounted system

b. Record your own

c. N.D.T. using pre-recorded hologram of Coke can 
All of these experiments were preceded by a mini-lecture on the subject with topical note-handouts. No work was taken home and all reports were written in class. Any help which was needed in writing the reports was provided by the well-staffed Writing Center at W.N.E.C. Such a group of students are shown in Figure 3. Members of the groups were encouraged to work together but to write separately. Students were chosen at random to read and explain what they had done in their laboratory class and what was observed. The students were encouraged to discover uses for the phenomena which they observed. The students were also expected to describe, as part of their experiment write-up, where these phenomena were seen in everyday life. Usually, in synchronous with the experiments, outside industrial visits and/or speakers were part of the topical study. In these visits, devices such as lenses (American Optical), fiber optic devices (Galileo Electro-Optics), liquid crystal displays (UCE, Inc.), diffractive systems (United Technologies), lasers (Coherent, Inc.), and holograms (United Technologies), were demonstrated, usually with reference to the product(s)/research which the company produced.

The use of computers for such concepts as lenses (Figure 4) and fiber optic communications (Figure 5) helped to show how more complex situations are aided by the use of a computer. The use of compact discs (shown in Figure 6), which everyone knew, as practical diffraction gratings was helpful in bringing home the real world applications. Making holography (Figure 7) work as a non-destructive test provided the students with a hands-on look at a very sophisticated technique.

Concepts such as seismic monitoring (mirrors on walls and floors with lasers at a distance), Fourier transforms, power generation, information transfer, and many other applications were explained at level by the college students to the junior high school students with great effectiveness. Students at the lower level caught the enthusiasm of those at the upper level and learned with retention.

\section{RESULTS AND DISCUSSION}

The learning experience for the junior high school students was long lasting and somewhat inspirational for all involved. Seven years into the program, the pros and cons are slanted heavily on the side of the pros. A number of these students are presently enrolled in both our college and numerous other institutions in the area. Many students were launched on the road to engineering and science due primarily to these experiences. Five of these students are taking, in addition to their first physics courses, their college courses in optics. They are doing quite well and recognize and use concepts and principles learned in the program taken in their earlier years.

The students from the college who had helped to teach these younger students stated that they learned a great deal of matter which they never really understood in their college class. Three of these student teachers are presently in Ph.D. programs in materials science and optical materials.

The professors involved in these programs have often spoken with pride of these years during which the program was fully active. Students now students in the college who were members of this junior high school group identify with and have excellent teacher/student rapport.

Problems which arose are common to these types of experiences. After three years of NSF/DOE funding, the amounts to carry on the program were reduced sharply. Outside industrial funding sources were sought with moderate success. A new program is being structured at present and funding is being sought from partnership organizations. The key words in this new funding cycle seem to be fiber optics, lasers, and communications. Other problems of logistics and, more infrequently, discipline are easily overcome with a bit of planning and "gentle authoritarianism", respectively.

In all, the experience was a productive and educationally healthy one for all involved. Other institutions have undertaken similar programs and are finding their own sets of surprises and problems. The experience was well worth the effort and the fruits of the labor were helpful in introducing the next wave of young scientists and students to the fascinating world of optics. 


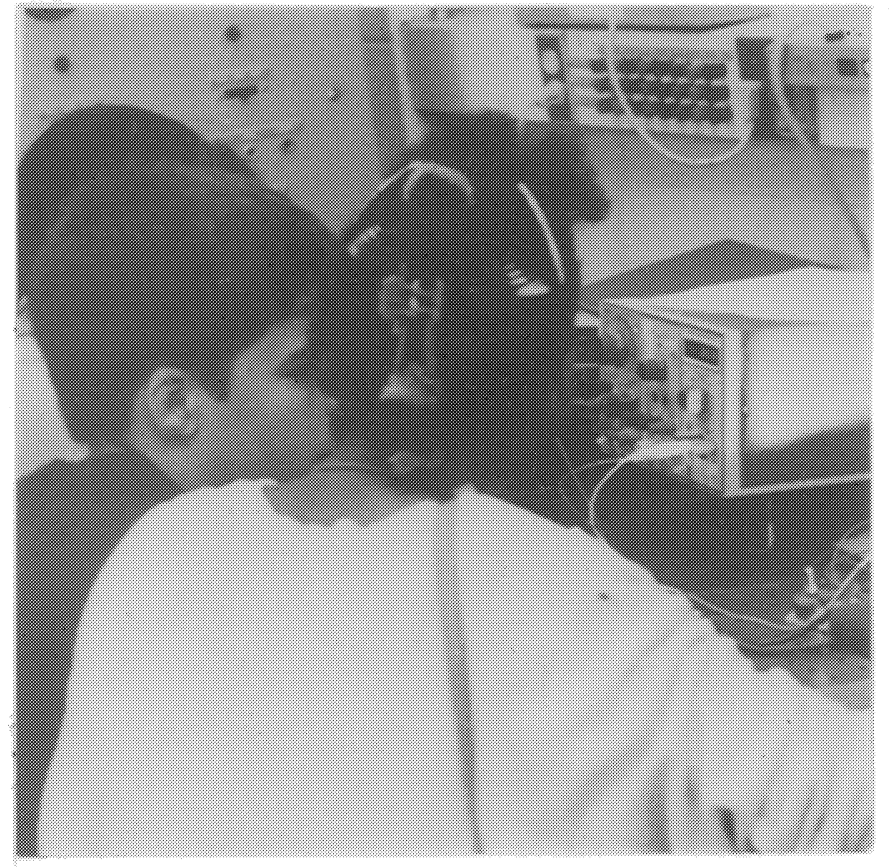

Figure 1 Typical working group

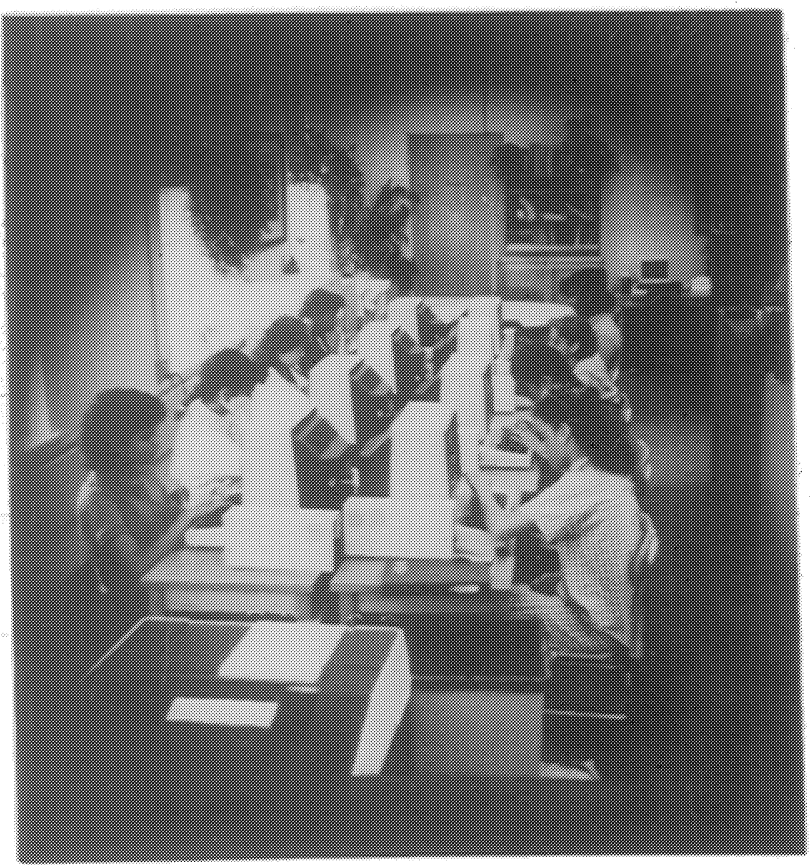

Figure 3 Group of students shown in writing center

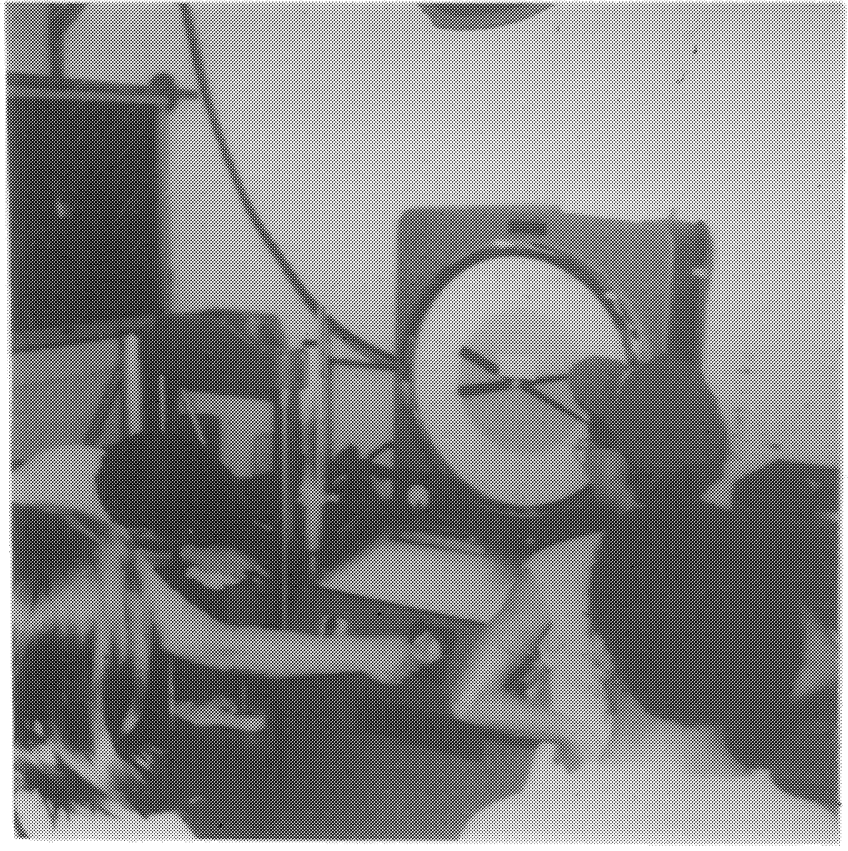

Figure 2 Research group working on laser tensile test vibration monitoring

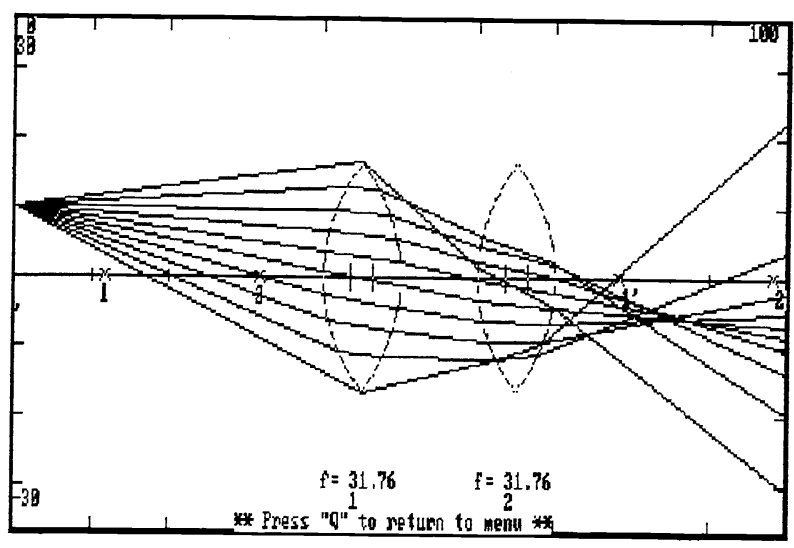

Figure 4 Lens program output 


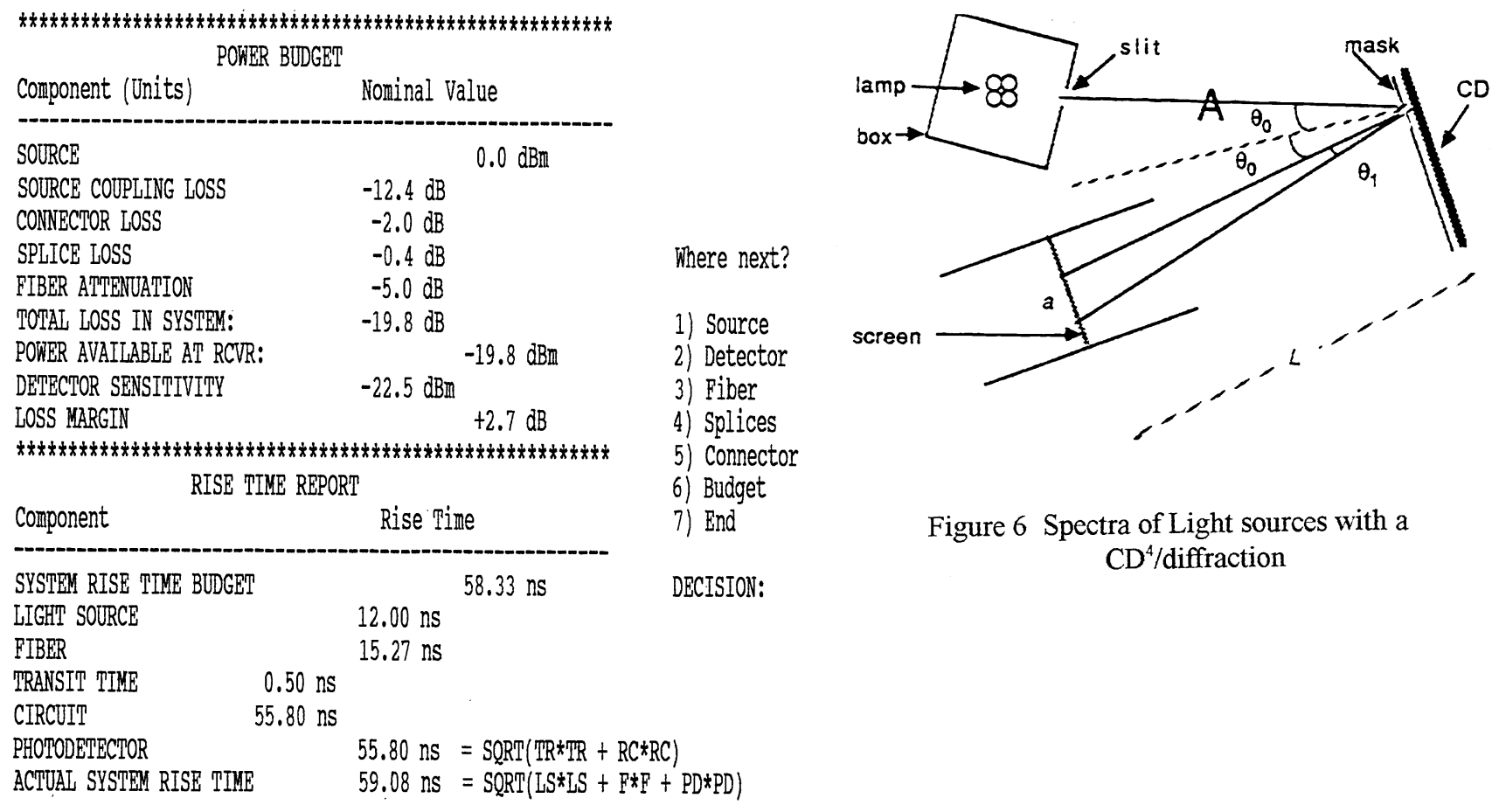

Figure 5 Fiber optic devices and communications

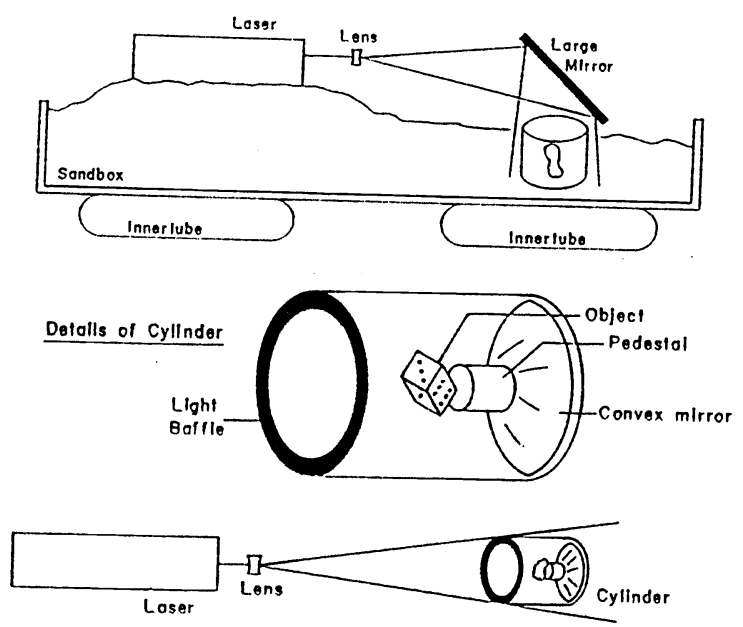

One Mirror Cyllndrical Hologram

Figure 7 Laser holographic setup

\section{REFERENCES}

1. J. Wilson and J.F.B. Hawkes, "Optoelectronics: An Introduction", Prentice Hall, 2nd Ed. 1992.

2. T. Anderson, "Raytrace: An Optical Raytracing Program", Kern International, Inc., Rockland, MA. 1985.

International, Inc. Rockland, MA. 1987.

4. C. Noldeke, Physics Teacher, 28, 383. 1990. 